\title{
Tipos de muerte celular y sus implicaciones clínicas
}

\author{
Types of cell death and their clinical implications \\ César Javier Carranza-Aguilar, ${ }^{*}$ Ana Karen Ruiz-Quiñonez, ${ }^{\ddagger}$ \\ Claudia González-Espinosa, ${ }^{\S}$ Silvia L Cruz-Martín-del-Campo ${ }^{\S}$
}

\begin{abstract}
RESUMEN. La muerte celular es un evento importante en el desarrollo embrionario, la renovación de los tejidos y el mantenimiento de la homeostasis del organismo. Errores en los mecanismos que regulan ese proceso están implicados en patologías como el cáncer, desórdenes neurodegenerativos, enfermedades autoinmunes, entre otras. La apoptosis es el tipo de muerte celular más estudiado debido a su importancia para el funcionamiento del organismo. Otros tipos de muerte celular como la necrosis, la piroptosis o la NETosis pueden producirse en respuesta a la producción de patrones moleculares asociados a patógenos o a daño, y generan una serie de respuestas encaminadas a la reparación tisular que, en ocasiones, tiene consecuencias adversas en el organismo. A lo largo de los años se ha pensado en evitar o inducir la muerte celular como terapia para ciertas patologías; sin embargo, muchos estudios no son concluyentes o arrojan resultados contradictorios. Actualmente existen algunas aproximaciones terapéuticas dirigidas a evitar o aumentar selectivamente la muerte celular para el tratamiento de algunos padecimientos como la enfermedad del Parkinson, cáncer, cirrosis y otras. En este artículo revisamos las características de los distintos tipos de muerte celular y algunas aproximaciones terapéuticas dirigidas a la regulación de tales procesos.
\end{abstract}

Palabras clave: Muerte celular, apoptosis, piroptosis, necrosis, NETosis.

ABSTRACT. Cell death is important in embryonic development, cell renewal and maintaining homeostasis. However, its malfunction is involved in the development of pathologies such as cancer, neurodegenerative disorders, tissue atrophy, and autoimmune diseases, among others. Apoptosis, or programmed cell death, is the most studied type of cell death and its importance lies in the fact that it is a common process that helps the body to function properly. Other types of cell death, such as necrosis, pyroptosis or NETosis can occur in the presence of molecular patterns associated with pathogens or damage, which produce unwanted responses

* Estudiante de doctorado en Neurofarmacología y Terapéutica Experimental.

‡ Estudiante de maestría en Neurofarmacología y Terapéutica Experimental.

$\S$ Investigadora titular.

Departamento de Farmacobiología. Centro de Investigación y de Estudios Avanzados (Cinvestav) del IPN, Sede Sur.

Recibido: 20 de Julio de 2020.

Aceptado: 28 de Agosto de 2020.

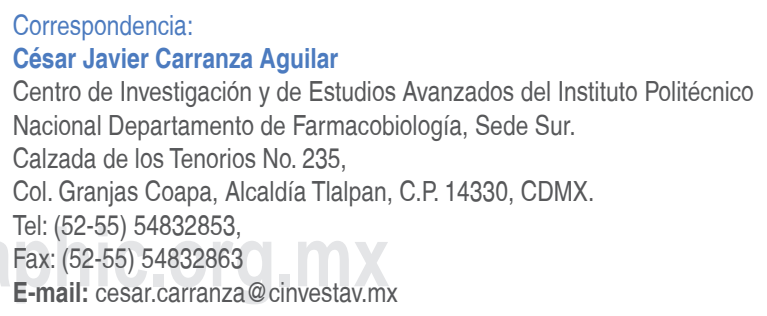

Conflicto de Intereses: Todos los autores declaran que no existe ningún conflicto de intereses con respecto a la publicación de este artículo.

Citar como: Carranza-Aguilar CJ, Ruiz-Quiñonez AK, González-Espinosa C, Cruz-Martín-del-Campo SL. Tipos de muerte celular y sus implicaciones clínicas. El Residente. 2020; 15 (3): 97-112. https://dx.doi.org/10.35366/95960 
in the organism. The induction or inhibition of cell death have been proposed as therapy for some diseases over the years, but the available studies are contradictory or not enough to determine the efficacy of such interventions. Currently, there are some therapeutic approaches to regulate cell death, for example, to avoid Parkinson's disease development, to reduce malignant cells in different types of cancer, to avoid liver damage induced by cirrhosis, and other disorders. In this paper we review the main features of different cell death mechanisms and some therapeutic approaches aimed at the regulation of this process.

Keywords: Cell death, apoptosis, pyroptosis, necrosis, NETosis.

\section{PANORAMA HISTÓRICO}

En 1847, el médico alemán Carl Vogt sugirió por primera vez que las células pueden morir de manera natural. En su estudio, el doctor Vogt hipotetizó que durante el estado embrionario de los anuros la formación de vértebras ocurría mediante un proceso de trasformación del cartílago para convertirse en hueso debido al reemplazamiento de las células presentes en la notocorda; sin embargo, su estudio no se enfocó en la muerte de las células. ${ }^{1}$ Fue hasta mediados del siglo XX cuando la muerte celular se comenzó a estudiar experimentalmente. ${ }^{2} \mathrm{Al}$ principio, este mecanismo se investigó como un proceso de desintegración celular que sucedía durante el desarrollo embrionario para la eliminación de órganos vestigiales y la construcción de órganos secundarios. ${ }^{3}$ En una notable revisión del campo, el médico Alfred Glucksmann describió la muerte celular como un proceso lento que involucra cambios estructurales tales como la formación de vacuolas citoplasmáticas, la disminución en el tamaño celular, la homogenización del contenido citoplasmático y la desaparición, en último término, del cuerpo celular. ${ }^{3}$

A finales de la década de 1960 y principios de los años 70, el patólogo John F Kerry y colaboradores investigaron la muerte celular como un proceso espontáneo. Los autores demostraron que este tipo de muerte es morfológicamente diferente a la necrosis producida por daño tisular. En 1972, estos investigadores propusieron el término apoptosis para denominar la muerte celular programada como un proceso natural cuyo término alude a una palabra griega que significa desprenderse de, al igual que los pétalos de una flor al paso del tiempo, y que ocurre como parte del proceso de generación de es-

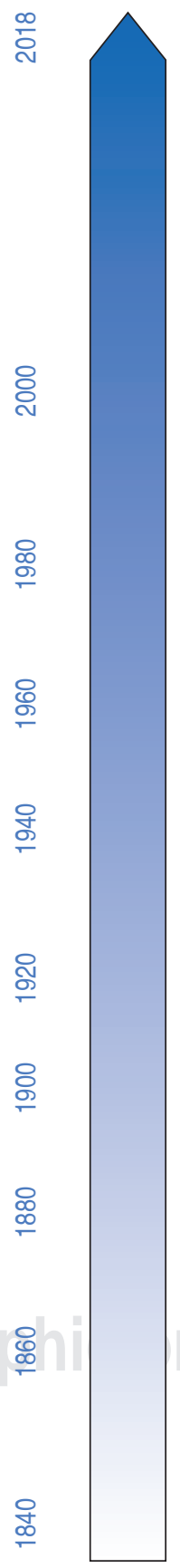

NCCD. Establecimiento de una nomenclatura para la clasificación de la muerte celular

Ohsumi Y. Premio Nobel de Medicina (2016): mecanismo de la autofagia

Brenner S, Sulston J, Horvitz R. Premio Nobel de Fisiología y Medicina (2002). Regulación genética de la organogénesis y la apoptosis en $C$. elegans

NCCD. Clasificación de apoptosis

Vaux DL. Bcl-2 es la primera proteína descubierta involucrada en la apoptosis

Kerr J. La necrosis por contracción es redefinida como apoptosis

Kerr J. Primera publicación sobre necrosis por contracción celular

Glücksmann A. Describe muerte celular en el desarrollo de vertebrados

Méchnikov I. Premio Nobel de Fisiología y Medicina (1908): fagocitosis importante en muerte celular

Felix W. Observa muerte celular en tejidos de mamíferos sanos

Flemming W. Define cromatólisis, equivalente a apoptosis

Virchow R. Define necrobiosis como muerte celular natural

Vogt C. Primera observación documentada de muerte celular en sapos

Figura 1: Eventos históricos significativos en el descubrimiento y el estudio de la muerte celular. 
tructuras nuevas en el organismo. ${ }^{4}$ A partir de este momento, se comenzó a estudiar la muerte celular como un componente importante en la regulación de diversos procesos fisiológicos. ${ }^{5}$

Los estudios de la muerte celular se han incrementado en los últimos años. ${ }^{6}$ La importancia de entender cómo y por qué se produce radica en su relevancia en diversos procesos fisiopatológicos y en que los múltiples mecanismos de la muerte se presentan dependiendo del tipo celular y del agente o estímulo inductor. ${ }^{7}$ En la Figura 1 se muestra un resumen de los principales eventos históricos sobre el descubrimiento y el estudio de la muerte celular.

\section{CARACTERÍSTICAS MORFOLÓGICAS, MOLECULARES Y FUNCIONALES DE LOS DIFERENTES TIPOS DE MUERTE CELULAR}

Una de las primeras clasificaciones de muerte celular se realizó con base en los cambios mor- fológicos distinguiendo tres tipos principales: apoptosis (tipo I), autofagia (tipo II) y necrosis (tipo III). ${ }^{8}$ En años más recientes, esta clasificación se ha modificado y extendido tomando en cuenta factores adicionales como el estímulo que induce el proceso de muerte y la maquinaria de señalización involucrada. ${ }^{9}$ Considerando esto, en 2018 el Comité de Nomenclatura sobre Muerte Celular (Nomenclature Committee on Cell Death, NCCD) propuso una nueva clasificación basada en aspectos moleculares. ${ }^{10}$

En la actualidad se reconoce que la muerte celular puede ser programada o no programada (Figura 2). La muerte celular no programada ocurre generalmente en condiciones de daño físico a los tejidos. ${ }^{11}$ En cambio, la muerte celular programada inicia por señales moleculares precisas que llevan a la célula a su muerte. ${ }^{12}$ Este tipo de muerte puede ser apoptótica o no apoptótica. La diferencia radica en que en la muerte celular apoptótica se mantiene la inte-

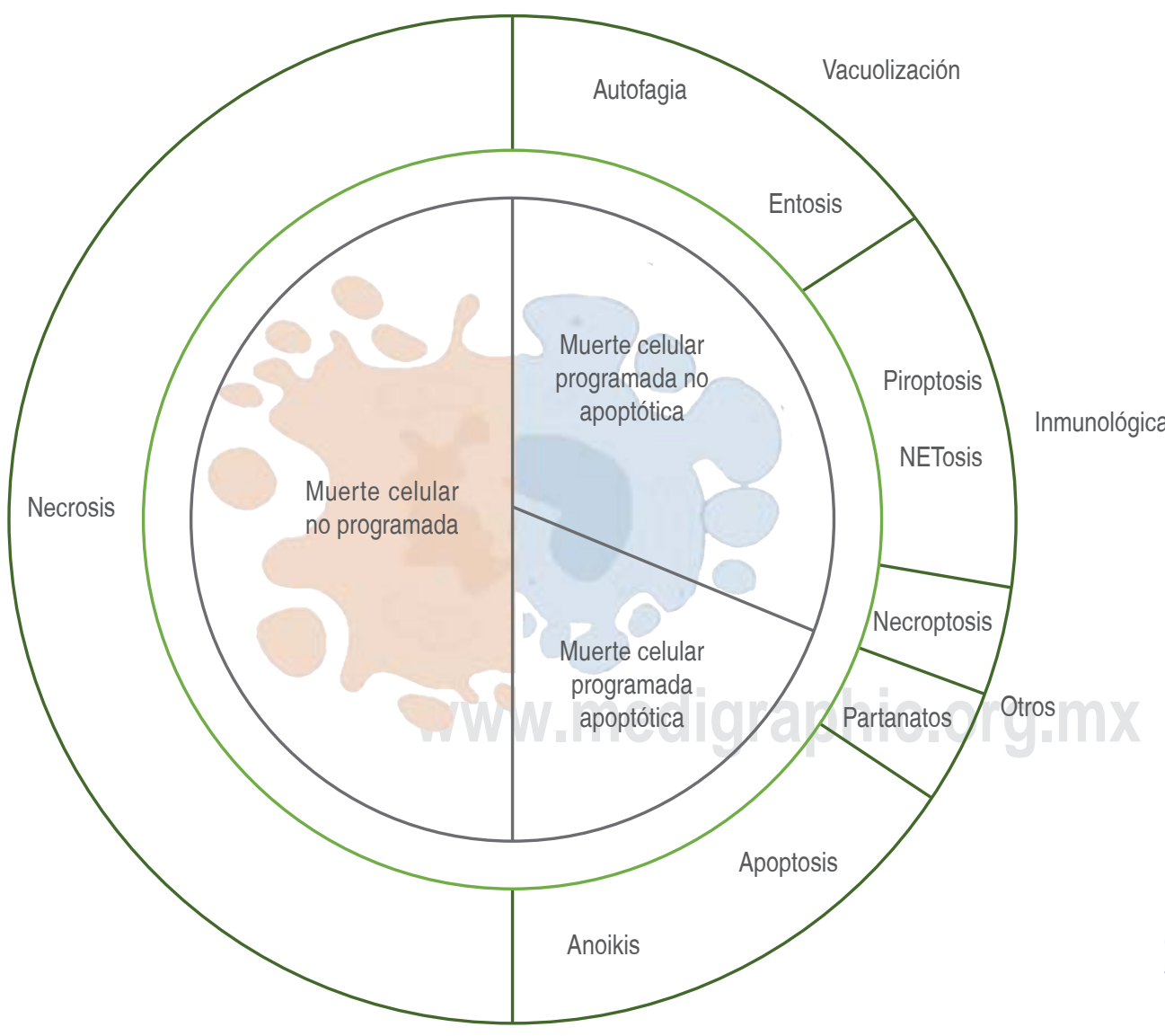

Figura 2:

Clasificación de la muerte celular con base en su función y sus características morfológicas. 
gridad de la membrana celular, hay ausencia de inflamación y se activan enzimas con actividad proteolítica. En contraste, la muerte celular no apoptótica se caracteriza por la ruptura de la membrana celular y la liberación de mediadores inflamatorios y del contenido citoplasmático al medio extracelular. ${ }^{13}$ En esta revisión describiremos los estímulos inductores, las características morfológicas y los aspectos moleculares de los principales tipos de muerte celular implicados en el desarrollo de diversas patologías.

\section{Necrosis}

La necrosis es un tipo de muerte accidental, o no programada, que ocurre cuando factores externos superan las condiciones fisiológicas del tejido y someten a la célula a un estrés excesivo e incontrolable. ${ }^{7}$ Ejemplos de estos factores son el calor, el frío, los estímulos mecánicos, varias sustancias químicas, la hipoxia, la radiación ionizante y la irradiación ultravioleta. ${ }^{14}$ En algunos casos, la necrosis puede disolver el tejido muerto, pero en otras ocasiones el tejido mantiene su arquitectura normal y los cambios celulares pueden observarse únicamente a nivel microscópico. ${ }^{11}$ Cuando una célula se encuentra en estado necrótico presenta hinchamiento de orgánulos, dilatación del retículo endoplásmico, ruptura temprana de la membrana plasmática y liberación "explosiva» del contenido citoplasmático al espacio extracelular. ${ }^{15}$

La muerte celular necrótica es un proceso pasivo que no requiere síntesis de novo de proteínas y emplea una cantidad mínima de energía. ${ }^{14}$ Se caracteriza por el aumento en el calcio intracelular $\left(\mathrm{Ca}^{2+}\right)$, la disfunción mitocondrial, el aumento en las especies reactivas de oxígeno (ROS, por sus siglas en inglés) y la proteólisis inducida por calpainas y catepsinas. ${ }^{16,17}$ Las calpainas son enzimas proteolíticas que tienen una cisteína en su sitio catalítico (por lo que también se les llama cisteína-peptidasas), no son lisosomales, y su actividad depende de calcio. Las catepsinas (del griego kathepsin, digerir) son proteasas que requieren un medio ligeramente ácido para funcionar.
En diversos escenarios clínicos la necrosis se reporta como resultado de trauma, isquemia o daño tisular. ${ }^{11,18}$ Otros reportes indican que este tipo de muerte se presenta en padecimientos neurodegenerativos como la enfermedad de Alzheimer, la enfermedad de Huntington, la enfermedad de Parkinson y la esclerosis lateral amiotrófica (ELA). ${ }^{16}$ Algunos autores han propuesto que, bajo ciertas condiciones de daño, la necrosis puede iniciarse de manera espontánea como un mecanismo para contribuir a la reparación del tejido. ${ }^{19}$ Sin embargo, los mecanismos moleculares que inducen la muerte necrótica en estas patologías no se conocen completamente.

\section{Apoptosis}

La apoptosis es el tipo de muerte celular programada más estudiado debido a que mantiene el balance fisiológico entre la proliferación y la eliminación celular. ${ }^{20}$ La detección de ligandos inductores de muerte, ácidos nucleicos, ROS, mediadores inflamatorios, toxinas y fármacos, entre otras sustancias, activa mecanismos que llevan a la célula a su propia destrucción. ${ }^{21}$ Estos ligandos pueden aumentar su concentración como consecuencia de un daño tisular que produzca la muerte de otras células, lo cual lleva a la liberación de su contenido al espacio extracelular. Una vez que la célula entra en apoptosis induce la activación de caspasas, que son proteasas con un residuo de cisteína (C) que fragmentan proteínas inmediatamente después de los residuos de aspartato (Asp). Las caspasas provocan el colapso de los componentes subcelulares, la condensación y fragmentación del ADN y la disminución del tamaño celular y nuclear. En este tipo de muerte, la integridad de la membrana plasmática se mantiene intacta hasta que comienza la formación de cuerpos apoptóticos, cuya función es contener el material celular y evitar que éste actúe como desencadenante de la muerte de otras células. Una vez finalizada la apoptosis, otras células especializadas fagocitan los cuerpos apoptóticos. ${ }^{22} \mathrm{~A}$ diferencia de la necrosis, la apoptosis no causa inflamación. ${ }^{23}$ 
Se han identificado tres vías que pueden conducir a la apoptosis. La primera se activa de manera extrínseca mediante la detección de ligandos endógenos como el factor de necrosis tumoral (TNF), el ligando Fas (FasL) o el ligando inductor de apoptosis relacionado al TNF (TRIAL). La activación de receptores de muerte (TNFR, Fas o DR5) induce la activación de la caspasa $8 .{ }^{24} \mathrm{La}$ segunda vía se activa de manera intrínseca por estímulos no dependientes de un receptor. La radiación o la hipoxia, por ejemplo, producen la apertura del poro de permeabilidad mitocondrial (MPT). La desregulación mitocondrial a su vez induce la liberación de proteínas proapoptóticas como el citocromo C y la proteína Smac/DIABLO que activan a otro tipo de caspasa, la caspasa $9 .{ }^{25}$ La tercera vía se produce por señales provenientes de linfocitos $\mathrm{T}$ citotóxicos. La activación de receptores de muerte celular programada como PD-1 (programmed cell death protein 1) induce la liberación de perforinas y granzimas que actúan sobre células infectadas con virus o células tumorales. Las perforinas forman poros en las células blanco a través de los cuales ingresan las granzimas. La granzima $\mathrm{B}$ induce la activación de la caspasa $10 .^{26}$ Las tres vías antes mencionadas convergen en la activación de la caspasa 3 , una enzima que produce la fragmentación del ADN, la degradación de proteínas del citoesqueleto, la formación de cuerpos apoptóticos y la expresión de ligandos que inducen el reclutamiento de células con capacidad fagocítica. ${ }^{12}$

La activación descontrolada de las caspasas sería incompatible con la vida, por eso se encuentran como zimógenos, es decir, como precursores enzimáticos inactivos que requieren de un cambio bioquímico para que se exponga su sitio activo y así puedan tener actividad catalítica. ${ }^{27}$ Además, existen proteínas reguladoras como la cinasa MEK o Bcl-2 (B-cell lymphoma 2) que actúan como proteínas antiapoptóticas cuya función principal es detener el progreso de la muerte celular programada. ${ }^{28}$

La disminución en la apoptosis favorece la proliferación celular en diferentes tipos de cán- cer y en patologías como el síndrome linfoproliferativo autoinmune, una enfermedad poco frecuente que aumenta el riesgo de desarrollar linfoma en las personas que la padecen. También, si disminuye la apoptosis puede presentarse una proliferación de sinoviocitos, que son las células que se producen en las membranas sinoviales de las articulaciones. Esto es relevante porque el aumento descontrolado de sinoviocitos contribuye a la destrucción de hueso y cartílago en la artritis reumatoide. ${ }^{29}$ En osteoartritis, la muerte de los condrocitos se da principalmente por apoptosis. A este tipo particular de muerte se le denomina condroptosis..$^{30} \mathrm{El}$ incremento en la apoptosis neuronal está involucrado en el desarrollo de enfermedades neurodegenerativas como el Alzheimer. ${ }^{31}$

\section{Necroptosis}

La necroptosis es un tipo de muerte cuyos cambios morfológicos son similares a los que se presentan en la necrosis, pero la necroptosis puede activarse por ligandos diferentes y está regulada por proteínas específicas. ${ }^{15}$ Las principales funciones de este tipo de muerte celular son: asegurar la eliminación de células infectadas por patógenos, promover un estado inflamatorio mediante la liberación de patrones moleculares asociados a daño (DAMPs, por sus siglas en inglés), e inducir el reclutamiento de células fagocíticas al sitio de daño, entre otras. $^{32}$

La muerte celular necroptótica se produce por la activación de receptores de membrana como los tipo toll 3/4 (TLR3/4), o los de muerte (death receptors o DRs). ${ }^{33}$ La activación de estos receptores induce la activación de cinasas que fosforilan residuos de serina o treonina (RIPKs, receptor-interacting protein kinases) y que interactúan con otros receptores. Las proteínas RIPK1 y RIPK3 se oligomerizan para formar un complejo intracelular denominado necroptosoma, el cual induce la activación de la proteína MLKL (mixed lineage kinase domain like pseudokinase). Esta proteína se transporta a la membrana celular para inducir su ruptura 
y, en consecuencia, la liberación del contenido citoplasmático. ${ }^{15}$

Se ha sugerido que la necroptosis es un mecanismo complementario a la apoptosis en algunas enfermedades neurodegenerativas. ${ }^{34}$ Además, se sabe que el estado inflamatorio que produce propicia el crecimiento de tumores en diversos tipos de cáncer tales como el de mama, el colorrectal o el osteosarcoma, entre otros. ${ }^{35}$ Un ejemplo particular donde se observa el proceso necrótico es en la fascitis necrosante de la piel que se caracteriza por la destrucción rápida del tejido y toxicidad sistémica.

\section{Piroptosis}

La piroptosis es un tipo de muerte celular inflamatoria que generalmente ocurre después de la detección intracelular de señales de daño o de patógenos. ${ }^{36}$ Las células piroptóticas presentan hinchamiento, fragmentación del material genético, formación de poros membranales, ruptura de la membrana plasmática y liberación de mediadores inflamatorios y del contenido citoplasmático al espacio extracelular. ${ }^{37}$ El lipopolisacárido (LPS), un componente de la cara externa de la pared celular de las bacterias Gram negativas, es uno de los principales activadores de la piroptosis en células del sistema inmunitario. ${ }^{38}$

El proceso de piroptosis requiere de dos estímulos. El primero es la activación de receptores de la inmunidad innata (como el receptor Tolllike-4, TLR4) que induce la activación del factor nuclear $-\kappa \mathrm{B}(\mathrm{NF}-\kappa \mathrm{B})$. Este factor de transcripción se transporta al núcleo e induce el aumento en la transcripción de los genes para pro-IL-1 $\beta$, pro-IL-18, y procaspasas, que son precursores inactivos de las respectivas citocinas inflamatorias (interleucina 1 b y 18) y de las caspasas. Como resultado de esta activación, también hay un aumento de receptores intracelulares tipo Nod (NLRs). Una segunda señal induce la oligomerización de complejos intracelulares denominados inflamasomas. ${ }^{39}$ Los inflamasomas promueven la maduración de pro-IL-1 $\beta$ y procaspasa- 1 a sus formas activas. Mientras la IL-
$1 \beta$ se libera e induce un estado proinflamatorio, la caspasa-1 rompe la proteína citoplasmática gasdermina D (GSDMD). La porción amino terminal de la GSDMD se transporta a la membrana y forma poros que provocan la muerte celular mediante la salida de componentes citoplasmáticos. ${ }^{40}$

El estado inflamatorio que produce la piroptosis está implicado en el desarrollo de cáncer de colon y cáncer gástrico. ${ }^{41}$ Además, este tipo de muerte celular participa en la inflamación aséptica dentro del sistema nervioso central (SNC) y se ha relacionado con las complicaciones producidas por enfermedades neurológicas como la encefalitis viral y la meningitis. En este sentido, la neuroinflamación inducida por la piroptosis puede contribuir a la pérdida de la memoria, la hipersensibilidad al dolor o los episodios convulsivos producidos en algunas enfermedades. ${ }^{42}$

\section{NETosis}

La NETosis o "muerte suicida de neutrófilos» es un mecanismo inducido por bacterias, hongos, virus, parásitos, citocinas, quimiocinas y algunos fármacos. ${ }^{43,44}$ Los principales cambios morfológicos que se observan en este tipo de muerte celular son: descondensación de la cromatina, ruptura de la membrana nuclear, mezcla del contenido nuclear y citoplasmático, ruptura de la membrana plasmática y liberación de trampas extracelulares de neutrófilos (NETs). ${ }^{45}$ Las NETs están formadas por material genético, histonas, elastasa, mieloperoxidasas y proteasas que permiten inmovilizar, neutralizar y combatir a agentes patógenos. ${ }^{46}$ Es decir, los neutrófilos se suicidan para combatir la infección.

La muerte celular por NETosis es independiente de caspasas e inicia cuando diversos ligandos endógenos o exógenos se unen a receptores TLR, receptores del complemento o receptores de citocinas. Dicha activación induce el incremento en el calcio intracelular y la activación de la proteína cinasa C (PKC) y de la enzima NADPH oxidasa. Estas proteínas 
promueven la producción de ROS, lo que contribuye a la ruptura de la envoltura nuclear. Estas señales activan a la enzima PAD4 que se transporta al núcleo y produce la citrulinación (conversión de arginina a citrulina, lo que conlleva a una alteración de la conformación espacial) de histonas y la descondensación de la cromatina. ${ }^{45} \mathrm{El}$ sistema inmunitario puede atacar a las proteínas citrulinadas. De hecho, el incremento de la NETosis y la liberación de NETs están relacionados con el desarrollo de enfermedades autoinmunes como la artritis reumatoide y la esclerosis múltiple. En específico, algunas moléculas que forman las NETs actúan como autoantígenos en enfermedades como la vasculitis positiva al antígeno citoplasmático de neutrófilos (ANCA) y el lupus eritematoso sistémico. ${ }^{47}$

\section{Autofagia}

La autofagia es un proceso autodegradativo necesario para equilibrar las fuentes de energía y de nutrientes en respuesta a factores que modifican la homeostasis celular. ${ }^{48}$ La autofagia participa en la eliminación de proteínas y orgánulos dañados, contribuye a la presentación de antígenos en la superficie celular, protege contra la inestabilidad del genoma y previene el daño tisular. Estas características le confieren un papel muy importante en el cáncer, la neurodegeración, la diabetes y diversas enfermedades hepáticas y autoinmunes. ${ }^{49}$ Elementos moleculares que llevan a este tipo de muerte celular colaboran también en la respuesta al estrés.

La autofagia se caracteriza por la degradación de sustancias intracelulares y extracelulares en los lisosomas de las células. La degradación de diversos componentes exógenos se lleva a cabo por endocitosis y fagocitosis; a este proceso se le conoce como macroautofagia, mientras que la degradación de componentes intracelulares se lleva a cabo por microautofagia y autofagia mediada por proteínas chaperonas. ${ }^{50}$

En la macroautofagia, los materiales exógenos y proteínas de membrana se fagoci- tan de manera no selectiva y se transportan al lisosoma mediante una vesícula de doble membrana denominada autofagosoma, que se fusiona con el lisosoma para formar un autolisosoma donde estos componentes son degradados. ${ }^{51}$ En la microautofagia, el material citoplasmático se detecta selectivamente y se transporta al interior de los lisosomas directamente, sin necesidad de pasar por otra vesícula. ${ }^{52}$ En el caso de la autofagia mediada por chaperonas, las proteínas dañadas se transportan hacia el interior de la célula después de la activación de proteínas de choque térmico, como la Hsp70, que aceleran el plegamiento de proteínas dañadas, protegen a proteínas intactas y son reconocidas por una proteína estructural de los lisosomas, llamada LAMP2. ${ }^{53}$

La acumulación de fagosomas y autofagosomas inducida por diversas señales llevan a la muerte de la célula. ${ }^{54}$ Se ha demostrado que la autofagia regula la progresión de diversos tipos de cáncer. ${ }^{55}$ Por ejemplo, la disminución de las proteínas beclina-1 y HIF-1 $\alpha$, importantes en la iniciación de la autofagia inducida por hipoxia, está involucrada en la proliferación de células cancerosas en leucemia mieloide aguda, leucemia linfoblástica y trastorno linfoproliferativo. ${ }^{56,57}$ Por el contrario, otras evidencias indican que el aumento en la autofagia en tumores sólidos de glioma, osteosarcoma y en tumores no sólidos de leucemia mieloide aguda puede inducir quimiorresistencia, aunque el mecanismo no se conoce completamente. Se ha propuesto que la autofagia protege de la muerte a las células cancerosas con resistencia a fármacos mediante la degradación de proteínas inductoras de apoptosis. El uso de inhibidores de la formación de fagosomas han resultado efectivos en estudios preclínicos para sensibilizar a las células tumorales al efecto de fármacos quimioterapéuticos. ${ }^{58}$

\section{Entosis}

En diversos tipos de cáncer se ha observado un mecanismo de muerte celular por caniba- 
lismo que consiste en el engullimiento completo de células viables por células circundantes con capacidad fagocítica. ${ }^{59}$ La célula que fagocita cumple la función de hospedera, mientras que la célula fagocitada, sujeta a destrucción, es la célula entótica. Una vez que la célula cancerosa se separa de la matriz extracelular, células circundantes la detectan a través del reconocimiento de las moléculas de adhesión E-cadherina y $\alpha$-catenina. ${ }^{59}$ La asociación entre ambas células se mantiene mediante fuerzas producidas por la polimerización de la actina. Para que una célula penetre dentro de otra, se requiere la activación de la GTPasa RhoA y de la cinasa ROCK, que son proteínas que inducen la acumulación de microfibras de actina y miosina. De esta manera, la actomiosina ejerce una fuerza contráctil que lleva a la célula entótica al interior de la célula hospedera. ${ }^{60,61}$ Ésta, a su vez, activa un mecanismo que induce la degradación lisosomal de la célula entótica. La entosis se ha ob-
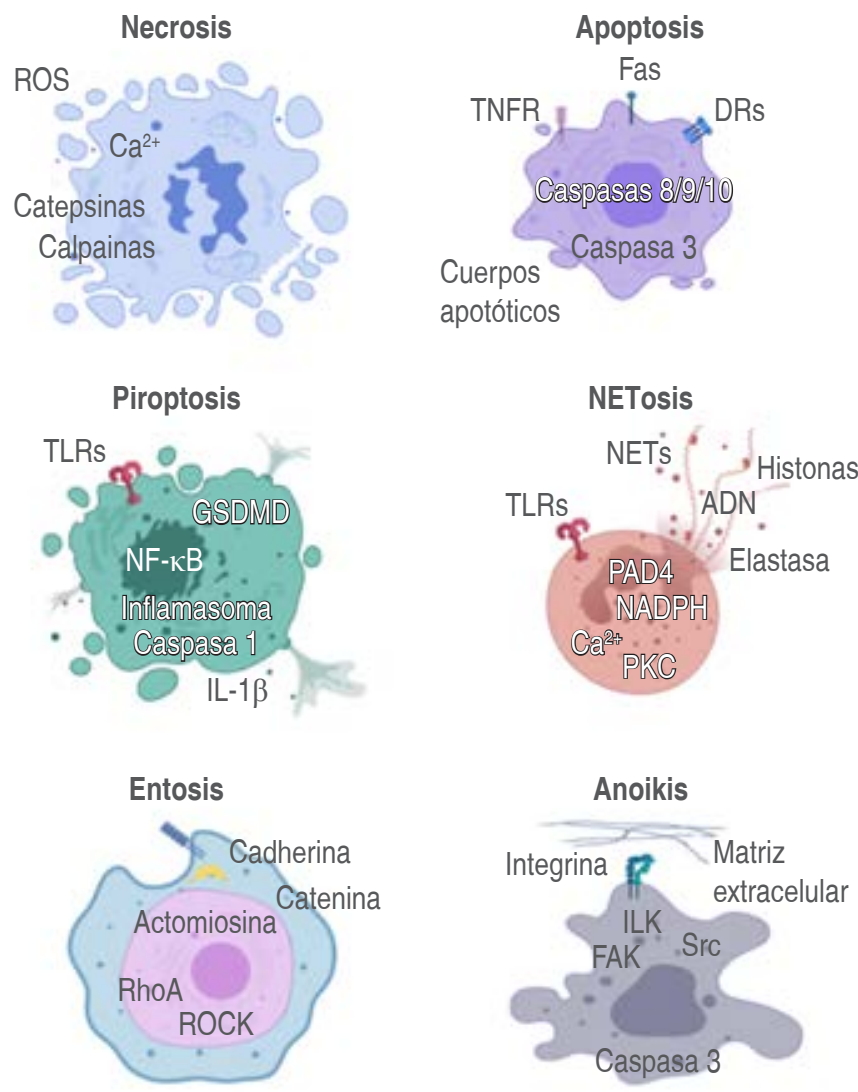

servado en células de cáncer epitelial humano y cáncer de mama. ${ }^{62,63}$

\section{Anoikis}

La anoikis es un tipo de apoptosis que inicia cuando la célula se desprende de la matriz extracelular circundante. Su nombre viene del griego oik, casa, y de la letra alfa privativa, que significa sin. Este proceso de muerte celular sirve para eliminar células que se encuentran en ubicaciones inapropiadas. La anoikis se modula por señales dependientes de integrinas membranales. La activación de integrinas induce la fosforilación de la cinasa unida a la integrina ILK, de la proteína tirosina-cinasa Src y de la cinasa de adhesión focal FAK. La activación de estas proteínas lleva a la activación de las vías intrínseca o extrínseca de la apoptosis. ${ }^{64}$ En el cáncer, las células que escapan de la anoikis por activación de la proteína PI3K pueden inducir metástasis. ${ }^{65}$
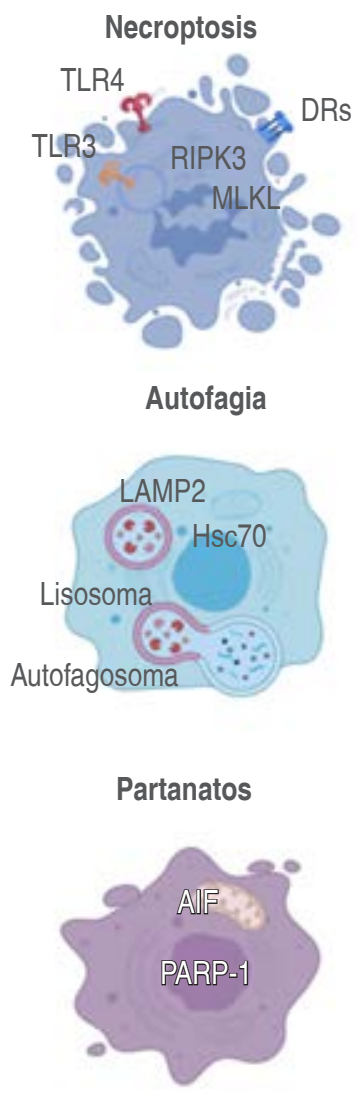

Figura 3:

Características moleculares y morfológicas distintivas de cada tipo de muerte celular. 


\section{Partanatos}

La muerte celular por partanatos se llama así porque depende de la acumulación de la enzima poli (ADP-ribosa) polimerasa-1 (PARP1) y por el término thanatos, palabra griega que significa muerte. En condiciones normales, la PARP-1 contribuye a la iniciación de las señales de reparación del daño al ADN. Sin embargo, la acumulación de esta proteína produce la activación mitocondrial del factor inductor de apoptosis o AIF por sus siglas en inglés. ${ }^{66}$ Este tipo de muerte celular es independiente de caspasas, induce la despolarización de la membrana mitocondrial, genera la producción de ROS y escapa del efecto antiapoptótico de Bcl-2. Se ha demostrado que la acumulación de PARP-1 se induce por lesión cerebral isquémica, por excitotoxicidad producida por niveles elevados del neurotransmisor N-metil-D-aspartato (NMDA) y durante la enfermedad de Parkinson. ${ }^{67}$ Es necesario extender la investigación de este tipo de muerte celular para comprender su papel en condiciones fisiológicas normales y durante la enfermedad. En la Figura 3 se resumen algunas características morfológicas y moleculares de cada tipo de muerte celular.

\section{TERAPÉUTICA DIRIGIDA A LA MODULACIÓN DE LA MUERTE CELULAR}

La modulación de las vías que conducen a la muerte celular representa un campo de estudio potencialmente innovador en la terapéutica dirigida hacia el tratamiento del cáncer, enfermedades inmunológicas, y trastornos neurodegenerativos, entre otros padecimientos. ${ }^{68} \mathrm{Sin}$ embargo, debido al papel de la muerte celular en los procesos fisiológicos normales, su modulación representa un gran reto para la medicina actual. Las principales aproximaciones preclínicas están dirigidas al bloqueo o la activación de caspasas, la inducción específica de la apoptosis, la regulación de proteínas aberrantes derivadas de defectos genéticos y el estudio de las diferencias en las vías de muerte de células normales y malignas. ${ }^{69-71}$ Más allá de los ensayos preclínicos, muchos grupos de investigación y compañías farmacéuticas se han enfocado en estudiar y promover el uso de fármacos dirigidos a la regulación de la muerte celular en pacientes con enfermedades específicas. ${ }^{72,73}$ Así, en las últimas décadas, se han aprobado varios compuestos que modifican procesos de muerte celular para el tratamiento de diversas enfermedades relacionadas; algunos de los cuales se muestran en la Tabla 1. En los siguientes párrafos se describen algunas aproximaciones clínicas enfocadas en la modulación de la muerte celular para el tratamiento de enfermedades específicas.

\section{Cáncer}

La mayoría de compuestos y proteínas, aprobados por la FDA (Food and Drug Administration) para regular la muerte celular están dirigidos al tratamiento del cáncer. ${ }^{74}$ Por ejemplo, se sabe que la expresión de la proteína antiapoptótica Bcl-2 se encuentra en niveles altos en el cáncer pulmonar de células pequeñas. Los inhibidores de Bcl-2, venetoclax y navitoclax han sido eficaces para combatir este tipo de cáncer. ${ }^{75,76}$ Otra proteína que representa un blanco terapéutico es la proteína de muerte celular programada PD-1. Cuando esta proteína se une a su ligando PD-L1, localizado en células tumorales, se suprime la respuesta y la proliferación de los linfocitos T. Este mecanismo lo utilizan los tumores para evadir la respuesta inmunitaria de los linfocitos T. ${ }^{77} \mathrm{El}$ anticuerpo nivolumab reconoce a PD-1 en la superficie de los linfocitos T y favorece la activación de la vía apoptótica mediada por perforinas y granzimas en las células tumorales. La inmunidad antitumoral producida por este anticuerpo ha sido eficaz contra el cáncer pulmonar de células no pequeñas como el melanoma y el carcinoma de células renales. ${ }^{78}$

La necroptosis es otro proceso que se observa en diversos tipos de cáncer. ${ }^{79}$ Fármacos como el dabrafenib y el sorafenib se han empleado para el tratamiento antineoplásico del melanoma y el cáncer renal, respectivamente. ${ }^{73}$ Estos 
Tabla 1: Aproximaciones terapéuticas aprobadas por la FDA para el tratamiento de enfermedades con base en la regulación de la muerte celular.

\begin{tabular}{|c|c|c|c|}
\hline Patologías & Fármaco o proteína & Blanco terapéutico & Acción \\
\hline Síndrome coronario agudo & Colchicina & $\begin{array}{l}\text { Activación de inflamasomas/ } \\
\text { inhibición de NETs }\end{array}$ & $\begin{array}{l}\text { Inductor de apoptosis } \\
\text { e inhibición del reclutamiento } \\
\text { de neutrófilos }\end{array}$ \\
\hline Melanoma & Dabrafenib & $\begin{array}{l}\text { Inhibición de RIPK3/inhibición } \\
\text { de MEK }\end{array}$ & $\begin{array}{l}\text { Prevención de necrosis e } \\
\text { inducción de apoptosis }\end{array}$ \\
\hline Enfermedad hepática & Emricasan & Inhibición de caspasas & $\begin{array}{l}\text { Inhibición de apoptosis de } \\
\text { hepatocitos }^{83}\end{array}$ \\
\hline $\begin{array}{l}\text { Neutropenia inducida por } \\
\text { quimioterapia }\end{array}$ & GM-CSF recombinante & $\begin{array}{l}\text { Estimulación de la prolifera- } \\
\text { ción de neutrófilos }\end{array}$ & $\begin{array}{l}\text { Inhibición de la apoptosis de } \\
\text { neutrófilos }{ }^{84}\end{array}$ \\
\hline Enfermedad de Crohn & Infliximab & Bloqueo de TNF & $\begin{array}{l}\text { Inductor de apoptosis de } \\
\text { linfocitos } T^{85}\end{array}$ \\
\hline $\begin{array}{l}\text { Carcinoma pulmonar de } \\
\text { pequeñas células }\end{array}$ & Navitoclax & Inhibidor de Bcl-2 & Inducción de apoptosis ${ }^{75}$ \\
\hline $\begin{array}{l}\text { Cáncer pulmonar de células } \\
\text { no pequeñas, melanoma } \\
\text { y carcinoma de células } \\
\text { renales }\end{array}$ & Nivolumab & Unión a PD-1 & $\begin{array}{l}\text { Activación de linfocitos T } \\
\text { y de apoptosis en células } \\
\text { tumorales }^{78}\end{array}$ \\
\hline Enfermedad de Alzheimer & Rasagilina & Activación de Bcl-2 & Inhibición de apoptosis ${ }^{86,87}$ \\
\hline Cáncer renal & Sorafenib & $\begin{array}{l}\text { Inhibición de RIPK3/Inhibición } \\
\text { de MEK }\end{array}$ & $\begin{array}{l}\text { Prevención de necrosis e } \\
\text { inducción de apoptosis }\end{array}$ \\
\hline $\begin{array}{l}\text { Carcinoma pulmonar de } \\
\text { pequeñas células }\end{array}$ & Venetoclax & Inhibición de Bcl-2 & Inducción de apoptosis ist,75,88 $^{7}$ \\
\hline
\end{tabular}

fármacos evitan la formación de necroptosomas mediante el bloqueo de RIPK3, mientras que mantienen su eficacia para producir apoptosis mediante la inhibición de la cinasa antiapoptótica MEK. ${ }^{73,80}$

\section{Trastornos inmunológicos}

Las enfermedades autoinmunes y el cáncer se asocian frecuentemente con alteraciones en la muerte de neutrófilos. ${ }^{81}$ Los tratamientos empleados hasta el momento buscan inhibir o activar la muerte de neutrófilos dependiendo de la enfermedad de que se trate. Por ejemplo, para evitar la neutropenia inducida por quimioterapia se administra el factor estimulante de colonias de granulocitos y macrófagos (GM-CSF), la fluticasona o la prednisolona. Estos compuestos estimulan la proliferación de neutrófilos al in- hibir la apoptosis. ${ }^{81,84}$ En cambio, la colchicina se ha empleado en enfermedades autoinmunes para inhibir el reclutamiento de neutrófilos y evitar la formación de NETs mediante la activación de inflamasomas. ${ }^{82,89,90}$

\section{Trastornos digestivos}

En el caso de la enfermedad intestinal inflamatoria crónica o enfermedad de Crohn se ha sugerido que está mediada por la respuesta incrementada de los linfocitos $\mathrm{T}$ y el aumento en los niveles de TNF. ${ }^{85}$ El uso de la inmunoglobulina anti-TNF infliximab ha sido efectivo para tratar este trastorno digestivo. El infliximab se une al TNF soluble y al TNF transmembranal (TNFtm) localizado en la mucosa gastrointestinal. Se ha sugerido que la neutralización del TNFtm produce la apoptosis de linfocitos $\mathrm{T}$ en un meca- 
nismo que requiere la activación de caspasas y la regulación de la proteína Bcl-2. ${ }^{85,91,92}$

\section{Neurodegeneración}

Con respecto a las enfermedades neurodegenerativas, se han desarrollado fármacos con propiedades neuroprotectoras. ${ }^{93}$ La rasagilina es un medicamento que se utiliza para evitar el daño producido por la enfermedad de Alzheimer mediante la regulación de la supervivencia y la muerte celular. ${ }^{72}$ En específico, la rasagilina activa a Bcl-2 y a la proteína cinasa c (PKC) para rescatar neuronas que entran en apoptosis. ${ }^{86,87}$

\section{Trastornos renales}

La inhibición de caspasas es una opción terapéutica para el tratamiento de diversas enfermedades. La cirrosis y la insuficiencia renal aguda se asocian con la muerte de hepatocitos mediada por caspasas. El inhibidor de caspasas emricasan se ha probado en pacientes con enfermedad hepática y ha sido bien aceptado y tolerado. Sin embargo, los mecanismos por los que actúa no están bien esclarecidos, pero se piensa que podría actuar al inhibir la muerte celular de hepatocitos..$^{78,94}$

\section{LIMITACIONES Y PERSPECTIVAS DE LA FARMACOTERAPIA ASOCIADA A LA REGULACIÓN DE LA MUERTE CELULAR}

La modulación de la muerte celular representa una herramienta prometedora en el tratamiento de diversas patologías. Sin embargo, la mayoría de los fármacos que intervienen en este proceso se encuentran actualmente en desarrollo o en fase preclínica. ${ }^{68}$ Esto se debe a que los intentos de tratar síntomas o enfermedades mediante la manipulación de la muerte celular no han tenido tanto éxito como lo sugerirían algunos estudios preclínicos. ${ }^{14}$ Por otra parte, aunque existen técnicas para la identificación de diferentes tipos de muerte celular, es necesario establecer métodos más rápidos y específicos que ayuden a establecer una relación directa entre la muerte celular y una enfermedad de- terminada. En la Tabla 2 se resumen las características morfológicas de los diferentes tipos de muerte celular y los métodos de detección más utilizados hasta el momento en la clínica. ${ }^{7}$

Existen varias razones por las cuales muchos fármacos no han llegado a la fase clínica. En la mayoría de las patologías, las células tienen intacta la maquinaria apoptótica, y son las proteínas reguladoras de ese proceso las que están afectadas. En este contexto, la célula puede usar caminos alternativos que la lleven a la muerte aun cuando uno se encuentre bloqueado. ${ }^{68}$ Por otra parte, dirigir un fármaco a un tipo específico de célula resulta extremadamente complicado porque su difusión en diversos tejidos podría afectar células sanas. ${ }^{95}$ Además, la regulación inespecífica de la muerte podría traer como consecuencia efectos secundarios no deseados, por ejemplo, la caspasa 8 , importante para la apoptosis, participa en la activación de linfocitos $\mathrm{T}$ y la diferenciación de macrófagos, por lo tanto su regulación podría comprometer la respuesta inmunológica. ${ }^{96}$ Finalmente, la mayoría de las patologías relacionadas con la muerte celular generan un microambiente que resulta intolerable para las células circundantes al tejido afectado. Este microambiente se caracteriza por cambios en el $\mathrm{pH}$, estrés oxidante, desregulación osmótica, ausencia de nutrientes y temperatura inadecuada, entre otros. Por lo tanto, aunque los tratamientos farmacológicos prevengan un tipo de muerte celular, la evidencia indica que la célula morirá por algún otro mecanismo debido al estrés en el que se encuentre inmersa. ${ }^{68}$

Aun con estas limitaciones, el descubrimiento de diversas formas de muerte celular involucradas en la patogénesis de trastornos específicos facilita la comprensión de la enfermedad y representa una posible ventaja en la búsqueda de terapias más eficaces y con menos efectos adversos. Ante el panorama creciente de información basada en evidencias, es necesario que en un futuro cercano los investigadores y los médicos consideren llevar la terapéutica dirigida hacia la muerte celular al siguiente nivel: la práctica clínica. 
Tabla 2: Características morfológicas y métodos de detección de los diferentes tipos de muerte celular.

\begin{tabular}{|c|c|c|c|}
\hline Tipo de muerte & Características morfológicas & Método de detección & $\begin{array}{l}\text { Tejidos empleados para } \\
\text { la detección }\end{array}$ \\
\hline \multirow[t]{3}{*}{ Necrosis } & Dilatación del retículo endoplásmico & $\begin{array}{l}\text { Detección de la actividad de la enzima } \\
\text { lactato deshidrogenasa }\end{array}$ & Biopsias de piel humana ${ }^{97-99}$ \\
\hline & Ruptura de la membrana plasmática & $\begin{array}{l}\text { Observación de la integridad de la } \\
\text { membrana por tinción de ADN }\end{array}$ & \\
\hline & $\begin{array}{l}\text { Liberación «explosiva» del contenido } \\
\text { citoplasmático }\end{array}$ & Tinción de hematoxilina-eosina & \\
\hline \multirow[t]{4}{*}{ Apoptosis } & $\begin{array}{l}\text { Disminución del tamaño celular y } \\
\text { nuclear }\end{array}$ & Prueba de caspasas & Biopsias de piel y sangre humana ${ }^{98}$ \\
\hline & $\begin{array}{l}\text { Colapso de componentes subcelu- } \\
\text { lares }\end{array}$ & Prueba de fragmentación del ADN & \\
\hline & $\begin{array}{l}\text { Condensación y fragmentación del } \\
\text { ADN }\end{array}$ & Prueba de anexina V & \\
\hline & Formación de cuerpos apoptóticos & Tinción de hematoxilina-eosina & \\
\hline \multirow[t]{3}{*}{ Necroptosis } & Hinchamiento celular & Tinción de Gram & Biopsias de piel humana $a^{98}$ \\
\hline & Ruptura de la membrana & $\begin{array}{l}\text { Observación de la integridad de la } \\
\text { membrana }\end{array}$ & \\
\hline & Disgregación de orgánulos & Anticuerpos específicos & \\
\hline \multirow[t]{5}{*}{ Piroptosis } & Hinchamiento celular y nuclear & $\begin{array}{l}\text { Observación de la integridad de la } \\
\text { membrana mediante microscopia de } \\
\text { fluorescencia }\end{array}$ & $\begin{array}{l}\text { Carcinoma hepatocelular humano } \\
\text { y cultivos hepáticos }\end{array}$ \\
\hline & $\begin{array}{l}\text { Condensación y fragmentación de la } \\
\text { cromatina }\end{array}$ & Anticuerpos específicos & \\
\hline & Formación de poros membranales & Inmunohistoquímica & \\
\hline & Ruptura de la membrana plasmática & Inmunofluorescencia & \\
\hline & $\begin{array}{l}\text { Liberación del contenido citoplasmá- } \\
\text { tico }\end{array}$ & & \\
\hline \multirow[t]{5}{*}{ NETosis } & Descondensación de la cromatina & $\begin{array}{l}\text { Observación de la morfología median- } \\
\text { te microscopia de fluorescencia }\end{array}$ & $\begin{array}{l}\text { Cultivos celulares de neutrófilos } \\
\text { murinos y humanos }{ }^{101}\end{array}$ \\
\hline & Ruptura de la membrana nuclear & Anticuerpos específicos & \\
\hline & $\begin{array}{l}\text { Mezcla del contenido nuclear } \\
\text { y citoplasmático }\end{array}$ & & \\
\hline & Ruptura de la membrana plasmática & & \\
\hline & $\begin{array}{l}\text { Liberación de trampas extracelulares } \\
\text { de neutrófilos }\end{array}$ & & \\
\hline \multirow[t]{2}{*}{ Autofagia } & Formación de vesículas intracelulares & Anticuerpos específicos & Cultivos celulares ${ }^{102}$ \\
\hline & Deformación de los orgánulos & Inmunohistoquímica & Células tumorales humanas ${ }^{102,103}$ \\
\hline Entosis & $\begin{array}{l}\text { Presencia de una célula dentro } \\
\text { de otra célula }\end{array}$ & $\begin{array}{l}\text { Observación morfológica mediante } \\
\text { microscopía de fluorescencia y } \\
\text { electrónica }\end{array}$ & $\begin{array}{l}\text { Células tumorales humanas } \\
\text { de pulmón, hígado, colon, páncreas, } \\
\text { próstata, estómago y mama }{ }^{104}\end{array}$ \\
\hline \multirow[t]{3}{*}{ Anoikis } & $\begin{array}{l}\text { Disminución del tamaño celular } \\
\text { y nuclear }\end{array}$ & Anticuerpos específicos & $\begin{array}{l}\text { Cultivos celulares de células. } \\
\text { de cáncer de pulmón }{ }^{105}\end{array}$ \\
\hline & $\begin{array}{l}\text { Condensación y fragmentación del } \\
\text { ADN }\end{array}$ & Tinción de hematoxilina-eosina & \\
\hline & Formación de cuerpos apoptóticos & & \\
\hline \multirow[t]{2}{*}{ Partanatos } & $\begin{array}{l}\text { Permeabilización de la membrana } \\
\text { externa mitocondrial }\end{array}$ & Anticuerpos específicos & Sangre humana ${ }^{95}$ \\
\hline & $\begin{array}{l}\text { Condensación y fragmentación } \\
\text { de la cromatina }\end{array}$ & $\begin{array}{l}\text { Detección de la despolarización } \\
\text { de la membrana mitocondrial } \\
\text { y estrés oxidante }\end{array}$ & \\
\hline
\end{tabular}




\section{BIBLIOGRAFÍA}

1. Clarke PGH, Clarke S. Nineteenth century research on naturally occurring cell death and related phenomena. Anat Embryol (Berl). 1996; 193 (2): 81-99. doi: 10.1007/ BF00214700.

2. Zakeri Z, Lockshin RA. Cell death: history and future. Adv Exp Med Biol. 2008; 615: 1-11. doi: 10.1007/978-14020-6554-5_1.

3. Glucksmann A. Cell deaths in normal vertebrate ontogeny. Biol Rev Camb Philos Soc. 1951; 26 (1): 59-86. doi: 10.1111/j.1469-185x.1951.tb00774.x.

4. Kerr JFR, Wyllie AH, Currie AR. Apoptosis: a basic biological phenomenon with wideranging implications in tissue kinetics. Br J Cancer. 1972; 26 (4): 239-257. doi: 10.1038/bjc.1972.33.

5. Curtin JF, Cotter TG. Apoptosis: historical perspectives. Essays Biochem. 2003; 39: 1-10. doi: 10.1042/bse0390001.

6. Knight RA, Melino G. Cell death in disease: from 2010 onwards. Cell Death Dis. 2011; 2 (9): e202-e202. doi: 10.1038/cddis.2011.89.

7. Yan G, Elbadawi M, Efferth T. Multiple cell death modalities and their key features (Review). World Acad Sci J March. 2020: 39-48. doi: 10.3892/wasj.2020.40.

8. Galluzzi L, Maiuri MC, Vitale I et al. Cell death modalities: classification and pathophysiological implications. Cell Death Differ. 2007; 14 (7): 1237-1243. doi: 10.1038/sj.cdd.4402148.

9. Green DR, Llambi F. Cell Death Signaling. Cold Spring Harb Perspect Biol. 2015; 7 (12): a006080. doi: 10.1101/ cshperspect.a006080.

10. Galluzzi L, Vitale I. Molecular mechanisms of cell death: recommendations of the Nomenclature Committee on Cell Death. Cell Death Differ. 2018; 25: 486-541. doi: 10.1038/ s41418-017-0012-4.

11. Adigun R, Basit H, Murray J. Necrosis, Cell (Liquefactive, Coagulative, Caseous, Fat, Fibrinoid, and Gangrenous), 2020. Available in: https://www.ncbi.nlm.nih.gov/books/ NBK430935/.

12. Elmore S. Apoptosis: a review of programmed cell death. Toxicol Pathol. 2007; 35 (4): 495-516. doi: 10.1080/01926230701320337.

13. Tait SWG, Ichim G, Green DR. Die another way-nonapoptotic mechanisms of cell death. J Cell Sci. 2014; 127 (10): 2135-2144. doi: 10.1242/jcs.093575.

14. Hotchkiss RS, Strasser A, McDunn JE, Swanson PE. Cell death in disease: mechanisms and emerging therapeutic concepts. N Engl J Med. 2009; 361 (16): 1570-1583. doi: 10.1056/NEJMra0901217.

15. Hanson B. Necroptosis: a new way of dying? Cancer Biol Ther. 2016; 17 (9): 899-910. doi: 10.1080/15384047.2016.1210732.

16. Artal-Sanz M, Tavernarakis N. Proteolytic mechanisms in necrotic cell death and neurodegeneration. FEBS Lett. 2005; 579 (15): 3287-3296. doi: 10.1016/j. febslet.2005.03.052.

17. Golstein P, Kroemer G. Cell death by necrosis: towards a molecular definition. Trends Biochem Sci. 2007; 32 (1): 37-43. doi: 10.1016/j.tibs.2006.11.001.
18. Martin LJ, Al-Abdulla NA, Brambrink AM, Kirsch JR, Sieber FE, Portera-Cailliau C. Neurodegeneration in excitotoxicity, global cerebral ischemia, and target deprivation: a perspective on the contributions of apoptosis and necrosis. Brain Res Bull. 1998; 46 (4): 281309. doi: 10.1016/S0361-9230(98)00024-0.

19. Zong WX, Thompson CB. Necrotic death as a cell fate. Genes Dev. 2006; 20 (1): 1-15. doi: 10.1101/gad.1376506.

20. Fleisher TA. Apoptosis. 1997; 78: 245-250. doi: 10.1016/ S1081-1206(10)63176-6.

21. Gordeziani M, Adamia G, Khatisashvili G, Gigolashvili G. Programmed cell self-liquidation (apoptosis). Ann Agrar Sci. 2017; 15 (1): 148-154. doi: 10.1016/j.aasci.2016.11.001.

22. Saraste A. Morphologic and biochemical hallmarks of apoptosis. Cardiovasc Res. 2000; 45 (3): 528-537. doi: 10.1016/S0008-6363(99)00384-3.

23. Yang Y, Jiang G, Zhang P, Fan J. Programmed cell death and its role in inflammation. Mil Med Res. 2015; 2 (1): 12. doi: 10.1186/s40779-015-0039-0.

24. Tummers B, Green DR. Caspase-8: regulating life and death. Immunol Rev. 2017; 277 (1): 76-89. doi: 10.1111/ imr.12541.

25. Li P, Zhou L, Zhao T et al. Caspase-9: structure, mechanisms and clinical application. Oncotarget. 2017; 8 (14): 23996-24008. doi: 10.18632/oncotarget.15098.

26. Talanian RV, Yang X, Turbov J et al. Granule-mediated Killing: Pathways for Granzyme B-initiated Apoptosis. J Exp Med. 1997; 186 (8): 1323-1331. doi: 10.1084/ jem.186.8.1323.

27. Shi Y. Caspase activation, inhibition, and reactivation: a mechanistic view. Protein Sci. 2004; 13 (8): 1979-1987. doi: 10.1110/ps.04789804.

28. Singh R, Letai A, Sarosiek K. Regulation of apoptosis in health and disease: the balancing act of BCL-2 family proteins. Nat Rev Mol Cell Biol. 2019; 20 (3): 175-193. doi: 10.1038/s41580-018-0089-8.

29. Favaloro B, Allocati N, Graziano V, Di Ilio C, De Laurenzi V. Role of apoptosis in disease. Aging (Albany NY). 2012; 4 (5): 330-349. doi: 10.18632/aging. 100459.

30. Roach HI, Aigner T, Kouri JB. Chondroptosis: a variant of apoptotic cell death in chondrocytes? Apoptosis. 2004; 9 (3): 265-277. doi: 10.1023/B:APPT.0000025803.17498.26.

31. Zangemeister-Wittke U, Simon H-U. ApoptosisRegulation and clinical implications. Cell Death Differ. 2001; 8 (5): 537-544. doi: 10.1038/sj.cdd.4400844.

32. Gong Y, Fan Z, Luo G et al. The role of necroptosis in cancer biology and therapy. Mol Cancer. 2019; 18 (1): 100. doi: 10.1186/s12943-019-1029-8.

33. Dhuriya YK, Sharma D. Necroptosis: a regulated inflammatory mode of cell death. J Neuroinflammation. 2018; 15 (1): 199. doi: 10.1186/s12974-018-1235-0.

34. Zhang S, Tang M, Luo H, Shi C, Xu Y. Necroptosis in neurodegenerative diseases: a potential therapeutic target. Cell Death Dis. 2017; 8 (6): e2905-e2905. doi: 10.1038/cddis.2017.286. 
35. Zhu F, Zhang W, Yang T, He S. Complex roles of necroptosis in cancer. J Zhejiang Univ B. 2019; 20 (5): 399-413. doi: 10.1631/jzus.B1900160.

36. Frank D, Vince JE. Pyroptosis versus necroptosis: similarities, differences, and crosstalk. Cell Death Differ. 2019; 26 (1): 99-114. doi: 10.1038/s41418-018-0212-6.

37. Bergsbaken T, Fink SL, Cookson BT. Pyroptosis: host cell death. Nat Rev Microbiol. 2009; 7 (2): 99-109. doi: 10.1038/nrmicro2070.Pyroptosis.

38. Nyström S, Antoine DJ, Lundbäck P et al. TLR activation regulates damage-associated molecular pattern isoforms released during pyroptosis. EMBO J. 2013; 32 (1): 86-99. doi: 10.1038/emboj.2012.328.

39. Kelley N, Jeltema D, Duan Y, He Y. The NLRP3 inflammasome: an overview of mechanisms of activation and regulation. Int J Mol Sci. 2019; 20 (13): 3328. doi: 10.3390/ijms20133328.

40. Shi J, Zhao Y, Wang K et al. Cleavage of GSDMD by inflammatory caspases determines pyroptotic cell death. Nature. 2015; 526 (7575): 660-665. doi: 10.1038/ nature 15514.

41. Zhou CB, Fang JY. The role of pyroptosis in gastrointestinal cancer and immune responses to intestinal microbial infection. Biochim Biophys Acta Rev Cancer. 2019; 1872 (1): 1-10. doi: 10.1016/j. bbcan.2019.05.001.

42. Zhao G, Xie Z. Pyroptosis and neurological diseases. Neuroimmunol Neuroinflammation. 2014; 1 (2): 60. doi: 10.4103/2347-8659.139716.

43. Delgado-Rizo V, Martínez-Guzmán MA, Iñiguez-Gutierrez L, García-Orozco A, Alvarado-Navarro A, Fafutis-Morris M. Neutrophil extracellular traps and its implications in inflammation: An overview. Front Immunol. 2017; 8: 1-20. doi: 10.3389/fimmu.2017.00081.

44. Irizarry-Caro JA, Carmona-Rivera C, Schwartz DM, Khaznadar SS, Kaplan MJ, Grayson PC. Brief report: drugs implicated in systemic autoimmunity modulate neutrophil extracellular trap formation. Arthritis Rheumatol. 2018; 70 (3): 468-474. doi: 10.1002/art.40372.

45. Rai G. NETosis: mechanisms and antimicrobial strategies. In: Sanchez-Zuniga JM. Netosis. Elsevier; 2019, pp. 23-55. doi: 10.1016/B978-0-12-816147-0.000022.

46. Rada B. Neutrophil extracellular traps. Methods Mol Biol. 2019; 1982: 517-528. doi: 10.1007/978-1-4939-94243_31.

47. Kaplan JM. Neutrophil extracelullar traps (NETs):Double-edged swords of innate immunity 1. 2013; 189 (6): 2689-2695. doi: 10.4049/jimmunol.1201719. Neutrophil.

48. Glick D, Barth S, Macleod KF. Autophagy: cellular and molecular mechanisms. J Pathol. 2010; 221 (1): 3-12. doi: http://doi.org/10.1002/path.2697. 10.1002/path.2697. Autophagy.

49. Yang Y, Klionsky DJ. Autophagy and disease: unanswered questions. Cell Death Differ. 2020; 27 (3): 858-871. doi: 10.1038/s41418-019-0480-9.
50. Parzych KR, Klionsky DJ. An overview of autophagy: morphology, mechanism, and regulation. Antioxid Redox Signal. 2014; 20 (3): 460-473. doi: 10.1089/ars.2013.5371.

51. Feng Y, He D, Yao Z, Klionsky DJ. The machinery of macroautophagy. Cell Res. 2014; 24 (1): 24-41. doi: 10.1038/cr.2013.168.

52. Li W, Li J, Bao J. Microautophagy: lesser-known selfeating. Cell Mol Life Sci. 2012; 69 (7): 1125-1136. doi: 10.1007/s00018-011-0865-5.

53. Kaushik S, Cuervo AM. Chaperone-mediated autophagy: a unique way to enter the lysosome world. Trends Cell Biol. 2012; 22 (8): 407-417. doi: 10.1016/j.tcb.2012.05.006.

54. Denton D, Kumar S. Autophagy-dependent cell death. Cell Death Differ. 2019; 26 (4): 605-616. doi: 10.1038/ s41418-018-0252-y.

55. You L, Jin S, Zhu L, Qian W. Autophagy, autophagyassociated adaptive immune responses and its role in hematologic malignancies. Oncotarget. 2017; 8 (7): 1237412388. doi: 10.18632/oncotarget.13583.

56. Qu X, Yu J, Bhagat G et al. Promotion of tumorigenesis by heterozygous disruption of the beclin 1 autophagy gene. J Clin Invest. 2003; 112 (12): 1809-1820. doi: 10.1172/ JCI20039.

57. Radwan SM, Hamdy NM, Hegab HM, El-Mesallamy HO. Beclin-1 and hypoxia-inducible factor-1 $\alpha$ genes expression: Potential biomarkers in acute leukemia patients. Cancer Biomarkers. 2016; 16 (4): 619-626. doi: 10.3233/CBM-160603.

58. Li X, Zhou Y, Li Y et al. Autophagy: a novel mechanism of chemoresistance in cancers. Biomed Pharmacother. 2019; 119: 109415. doi: 10.1016/j.biopha.2019.109415.

59. Durgan J, Florey O. Cancer cell cannibalism: Multiple triggers emerge for entosis. Biochim Biophys ActaMol Cell Res. 2018; 1865 (6): 831-841. doi: 10.1016/j. bbamcr.2018.03.004.

60. Krishna S, Overholtzer M. Mechanisms and consequences of entosis. Cell Mol Life Sci. 2016; 73 (11-12): 2379-2386. doi: 10.1007/s00018-016-2207-0.

61. Zeng C, Zeng B, Dong C, Liu J, Xing F. Rho-ROCK signaling mediates entotic cell death in tumor. Cell Death Discov. 2020; 6 (1): 10-12. doi: 10.1038/s41420-020-0238-7.

62. Sun Q, Cibas ES, Huang H, Hodgson L, Overholtzer M. Induction of entosis by epithelial cadherin expression. Cell Res. 2014; 24 (11): 1288-1298. doi: 10.1038/ cr.2014.137.

63. Ruan B, Niu Z, Jiang X et al. High frequency of cell-incell formation in heterogeneous human breast cancer tissue in a patient with poor prognosis: a case report and literature review. Front Oncol. 2019; 9: 1-6. doi: 10.3389/ fonc.2019.01444.

64. Guadamillas MC, Cerezo A, del Pozo MA. Overcoming anoikis-pathways to anchorage-independent growth in cancer. J Cell Sci. 2011; 124 (19): 3189-3197. doi: 10.1242/ jcs.072165.

65. Paoli P, Giannoni E, Chiarugi P. Anoikis molecular pathways and its role in cancer progression. Biochim Biophys Acta. 2013; 1833 (12): 3481-3498. doi: 10.1016/j. bbamcr.2013.06.026. 
66. Fatokun AA, Dawson VL, Dawson TM. Parthanatos: mitochondrial-linked mechanisms and therapeutic opportunities. Br J Pharmacol. 2014; 171 (8): 2000-2016. doi: 10.1111/bph.12416.

67. Robinson N, Ganesan R, Hegedús C, Kovács K, Kufer TA, Virág L. Programmed necrotic cell death of macrophages: focus on pyroptosis, necroptosis, and parthanatos. Redox Biol. 2019; 26: 101239. doi: 10.1016/j.redox.2019.101239.

68. Lockshin RA, Zakeri Z. Cell death in health and disease. J Cell Mol Med. 2007; 11 (6): 1214-1224. doi: 10.1111/j.15824934.2007.00150.x.

69. Fischer U, Schulze-Osthoff K. Apoptosis-based therapies and drug targets. Cell Death Differ. 2005; 12 (S1): 942961. doi: 10.1038/sj.cdd.4401556.

70. Pfeffer CM, Singh ATK. Apoptosis: a target for anticancer therapy. Int J Mol Sci. 2018; 19 (2): 448. doi: 10.3390/ ijms19020448.

71. Kaminskyy VO, Zhivotovsky B. Cell death-based treatment of various diseases: a fifty-year journey. Cell Death Dis. 2018; 9 (2): 110. doi: 10.1038/s41419-017-01683.

72. Green DR, Kroemer G. Pharmacological manipulation of cell death: clinical applications in sight? J Clin Invest. 2005; 115 (10): 2610-2617. doi: 10.1172/JCI26321.

73. Fulda S. Repurposing anticancer drugs for targeting necroptosis. Cell Cycle. 2018; 17 (7): 829-832. doi: 10.1080/15384101.2018.1442626.

74. Derakhshan A, Chen Z, Waes C Van. Therapeutic small molecules target inhibitor of apoptosis proteins in cancers with deregulation of extrinsic and intrinsic cell death pathways. 2017; 1: 1379-1388. doi: 10.1158/1078-0432. CCR-16-2172.

75. Rudin CM, Hann CL, Garon EB et al. Phase II study of single-agent navitoclax (ABT-263) and biomarker correlates in patients with relapsed small cell lung cancer. Clin Cancer Res. 2012; 18 (11): 3163-3169. doi: 10.1158/1078-0432.CCR-11-3090.

76. Lochmann TL, Floros K V., Naseri M et al. Venetoclax is effective in small-cell lung cancers with high BCL-2 expression. Clin Cancer Res. 2018; 24 (2): 360-369. doi: 10.1158/1078-0432.CCR-17-1606.

77. Gong J, Chehrazi-Raffle A, Reddi S, Salgia R. Development of PD-1 and PD-L1 inhibitors as a form of cancer immunotherapy: a comprehensive review of registration trials and future considerations. J Immunother Cancer. 2018; 6 (1): 8. doi: 10.1186/s40425018-0316-z.

78. Guo L, Zhang H, Chen B. Nivolumab as programmed death-1 (PD-1) inhibitor for targeted immunotherapy in tumor. J Cancer. 2017; 8 (3): 410-416. doi: 10.7150/ jca.17144.

79. Pan P, Cai Z, Zhuang C, Chen X, Chai Y. Methodology of drug screening and target identification for new necroptosis inhibitors. J Pharm Anal. 2019; 9 (2): 71-76. doi: 10.1016/j.jpha.2018.11.002.

80. Roulstone V, Pedersen M, Kyula J et al. BRAF- and MEK-targeted small molecule inhibitors exert enhanced antimelanoma effects in combination with oncolytic reovirus through ER stress. Mol Ther. 2015; 23 (5): 931942. doi: 10.1038/mt.2015.15.

81. Brostjan C, Oehler R. The role of neutrophil death in chronic inflammation and cancer. Cell Death Discov. 2020; 6 (1): 26. doi: 10.1038/s41420-020-0255-6.

82. Tucker B, Vaidya K, Kurup R et al. Colchicine inhibits neutrophil extracellular trap formation in acute coronary syndrome patients post percutaneous coronary intervention. J Am Coll Cardiol. 2020; 75 (11): 1346. doi: 10.1016/S0735-1097(20)31973-2.

83. Van Opdenbosch N, Lamkanfi M. Caspases in cell death, inflammation, and disease. Immunity. 2019; 50 (6): 13521364. doi: 10.1016/j.immuni.2019.05.020.

84. Mehta HM, Malandra M, Corey SJ. G-CSF and GM-CSF in Neutropenia. J Immunol. 2015; 195 (4): 1341-1349. doi: 10.4049/jimmunol.1500861.

85. Ten Hove T. Infliximab treatment induces apoptosis of lamina propria T lymphocytes in Crohn's disease. Gut. 2002; 50 (2): 206-211. doi: 10.1136/gut.50.2.206.

86. Youdim MBH, Amit T, Falach-Yogev M, Am OB, Maruyama W, Naoi M. The essentiality of Bcl-2, PKC and proteasome-ubiquitin complex activations in the neuroprotective-antiapoptotic action of the antiParkinson drug, rasagiline. Biochem Pharmacol. 2003; 66 (8): 1635-1641. doi: 10.1016/S0006-2952(03)00535-5.

87. Nayak L, Henchcliffe C. Rasagiline in treatment of Parkinson's disease. Neuropsychiatr Dis Treat. 2008; 4 (1): 23-32. Available in: http://www.ncbi.nlm.nih.gov/ pubmed/18728823.

88. Pollyea DA, Amaya M, Strati P, Konopleva MY. Venetoclax for AML: changing the treatment paradigm. Blood Adv. 2019; 3 (24): 4326-4335. doi: 10.1182/ bloodadvances.2019000937.

89. Leung YY, Yao Hui LL, Kraus VB. Colchicine-Update on mechanisms of action and therapeutic uses. Semin Arthritis Rheum. 2015; 45 (3): 341-350. doi: 10.1016/j. semarthrit.2015.06.013.

90. Vaidya K, Martínez G, Patel S. The role of colchicine in acute coronary syndromes. Clin Ther. 2019; 41 (1): 11-20. doi: 10.1016/j.clinthera.2018.07.023.

91. Lichtenstein GR, Feagan BG, Cohen RD et al. Infliximab for Crohn's disease: more than 13 years of real-world experience. Inflamm Bowel Dis. 2018; 24 (3): 490-501. doi: 10.1093/ibd/izx072.

92. Billmeier U, Dieterich W, Neurath MF, Atreya R. Molecular mechanism of action of anti-tumor necrosis factor antibodies in inflammatory bowel diseases. World J Gastroenterol. 2016; 22 (42): 9300. doi: 10.3748/wjg.v22. i42.9300.

93. Morris G, Walker AJ, Berk M, Maes M, Puri BK. Cell death Pathways: a novel therapeutic approach for neuroscientists. 2018; 55: 5767-5786. doi: 10.1007/s12035017-0793-y.

94. Mehta G, Rousell S, Burgess G et al. A placebo-controlled, multicenter, double-blind, phase 2 randomized trial of the pan-caspase inhibitor Emricasan in patients with acutely decompensated cirrhosis. J Clin Exp Hepatol. 2018; 8 (3): 224-234. doi: 10.1016/j.jceh.2017.11.006. 
95. Lutz H, Hu S, Dinh P-U, Cheng K. Cells and cell derivatives as drug carriers for targeted delivery. Med Drug Discov. 2019; 3: 100014. doi: 10.1016/j. medidd.2020.100014.

96. Salmena L, Lemmers B, Hakem A et al. Essential role for caspase 8 in T-cell homeostasis and T-cell-mediated immunity. Genes Dev. 2003; 17 (7): 883-895. doi: 10.1101/ gad.1063703.

97. Hietbrink F, Bode LG, Riddez L, Leenen LPH, van Dijk MR. Triple diagnostics for early detection of ambivalent necrotizing fasciitis. World J Emerg Surg. 2016;11:51. doi: 10.1186/s13017-016-0108-z.

98. Afonso MB, Rodrigues PM, Simão AL et al. Activation of necroptosis in human and experimental cholestasis. Cell Death Dis. 2016; 7 (9): e2390-e2390. doi: 10.1038/ cddis.2016.280.

99. Chu Q, Jiang Y, Zhang W et al. Pyroptosis is involved in the pathogenesis of human hepatocellular carcinoma. Oncotarget. 2016; 7 (51): 84658-84665. doi: 10.18632/ oncotarget.12384.

100. Carmona-Rivera C, Purmalek MM, Moore E et al. A role for muscarinic receptors in neutrophil extracellular trap formation and levamisole-induced autoimmunity. JCI insight. 2017; 2 (3): 1-15. doi.org/10.1172/jci. insight.89780.

101. Orhon I, Fulvio R. Assays to monitor autophagy progression in cell cultures. Cells. 2017; 6 (3): 20. doi: 10.3390/cells6030020.

102. He H, Yang Y, Xiang Z et al. A sensitive IHC method for monitoring autophagy-specific markers in human tumor xenografts. J Biomarkers. 2016; 2016: 1-11. doi: 10.1155/2016/1274603.

103. Huang H, Chen A, Wang T et al. Detecting cell-in-cell structures in human tumor samples by E-cadherin/CD68/ CD45 triple staining. Oncotarget. 2015; 6 (24): 20278 20287. doi: 10.18632/oncotarget.4275.

104. Prateep A, Sumkhemthong S, Karnsomwan W et al. Avicequinone B sensitizes Anoikis in human lung cancer cells. J Biomed Sci. 2018; 25 (1): 32. doi: 10.1186/s12929018-0435-3.

105. Bárány T, Simon A, Szabó G et al. Oxidative stressrelated parthanatos of circulating mononuclear leukocytes in heart failure. Oxid Med Cell Longev. 2017; 2017: 1249614. doi: 10.1155/2017/1249614. 